\title{
Epidemiology of Methicillin-Resistant
} Staphylococcus Aureus Bloodstream Infections from 2013-2017 at Chiang Mai University: What Changes Occurred from 2007-2011?

\section{Kawisara Krasaewes}

Chiang Mai University Faculty of Medicine

Saowaluck Yasri

Chiang Mai University Faculty of Medicine

Phadungkiat Khamnoi

Chiang Mai University Faculty of Medicine

Romanee Chaiwarith ( $\sim$ rchaiwar@gmail.com )

Chiang Mai University

\section{Research article}

Keywords: MRSA, bloodstream infections, epidemiology, vancomycin MIC

Posted Date: June 8th, 2020

DOI: https://doi.org/10.21203/rs.3.rs-32103/v1

License: (a) (i) This work is licensed under a Creative Commons Attribution 4.0 International License.

Read Full License 


\section{Abstract}

Background: Methicillin-resistant Staphylococcus aureus (MRSA) is an established pathogen that causes hospital- acquired infections worldwide. Bloodstream infection is associated with significant morbidity and mortality. We conducted a study aimed at describing the epidemiology of MRSA bloodstream infections, to determine the minimal inhibitory concentration (MIC) of the antibiotic vancomycin among MRSA isolates, and to determine the rate and risk factors of mortality.

Methods: A retrospective study was conducted among patients aged $\geq 18$ years whose blood culture grew MRSA at Chiang Mai University from January 2013 to December 2017

Results: The annual prevalence of MRSA in S.aureus bloodstream infections from 2013 to 2017 were $32.8,23.1,26.8,19.2$ and $15.4 \%$, respectively. This prevalence showed a non-significant decrease $(p=$ 0.086). Eighty-four patients with 84 episodes of MRSA bloodstream infections were enrolled. Fifty-three patients $(63.1 \%)$ were male, and the median age was 68.5 years (IQR 56,79$)$. Fifty-eight patients $(69 \%)$ had bloodstream infections with other sites of infection: pneumonia (28 episodes, $43.1 \%$ ), skin and soft tissue infections (16 episodes, $24.6 \%$ ), osteomyelitis (7 episodes, $10.8 \%$ ), infective endocarditis (4 episodes, 6.2\%), septic arthritis (4 episodes, 6.2\%), arterial graft infections (4 episodes, $6.2 \%$ ), and urinary tract infections (2 episodes, 3.1\%). Percentage of patients with vancomycin MICs $\geq 1.5 \mathrm{mg} / \mathrm{L}$ were $68.2 \%$, $62.5 \%, 47.4 \%, 26.7 \%$, and $75 \%$ from 2013 to 2017 , respectively. $(p=0.325)$. The mortality rate was $64.3 \%$. There was no significant difference in mortality rate between those infected with MRSA with a MIC of vancomycin $<1.5$ and $\geq 1.5 \mathrm{mg} / \mathrm{L}(p=0.172)$. Factors associated with mortality included age $\geq 40$ years old (OR 11.35; 95\% Cl: $1.35-95.78, p=0.026)$, presence of alteration of consciousness (OR 11.19; $95 \% \mathrm{Cl}$ : $2.83-44.18, \mathrm{p}=0.001$ ) and concurrent pneumonia (OR 4.44; $95 \% \mathrm{Cl}: 1.09-18.14, p=0.038$ ).

Conclusions: Methicillin-resistance among Staphylococcus aureus bloodstream infections showed a nonsignificant decrease of 50\%, from 32.88\% and $15.4 \%$, between 2013 and 2017 . Concurrent infection with pneumonia increased mortality. Although the vancomycin MIC was unchanged from 2013 to 2017, the mean MICs were $>1.0 \mathrm{mg} / \mathrm{L}$. Careful monitoring of vancomycin MIC creep is crucial for the selection of the appropriate antibiotic dosage to prevent treatment failure.

\section{Background}

Methicillin-resistant Staphylococcus aureus (MRSA) is an established pathogen that causes hospitalacquired infections worldwide.[1] MRSA bloodstream infection (BSI) is associated with significant morbidity and mortality.[2] The prevalence rate of methicillin resistance among S.aureus infections varies widely depending upon the study site and the year of the study. The SENTRY antimicrobial surveillance program collected 191, 460 S. aureus isolates from 427 centers globally.[3] From 1997 to 2016, the prevalence of MRSA among $S$. aureus ranged between $26.8 \%$ in Europe and $47.0 \%$ in North America. In the Asia-Pacific area, which includes Thailand, the prevalence was 39.6\%. Among hospital-acquired S. aureus BSI, the prevalence of MRSA ranged from $37.8-45.3 \%$. The ANSORP study group collected the 
isolates from 2004 to 2006 in Asian countries and found that the prevalence of MRSA among S.aureus isolates was highest in Sri Lanka (86.5\%) and lowest in India (22.6\%).[4] In Thailand, the prevalence of MRSA among S.aureus isolates from university hospitals from 2005-2006 was 57\%, [4] and from 20122015 was $46.0 \%$.[5] A study from northeastern Thailand reported the prevalence of MRSA among $S$. aureus BSI during 2006-2007 was 28\%.[6] A prevalence of MRSA among S.aureus BSI of $23-43 \%$ during 2007-2011 from northern Thailand was also reported.[7]

Vancomycin is the mainstay treatment for MRSA infection. However, infections caused by MRSA with reduced susceptibility to vancomycin have been reported including some cases in Thailand.[8-12] In addition, there have been increasing reports about patients who had treatment failure from vancomycin, despite their vancomycin MIC being $\leq 2 \mathrm{mg} / \mathrm{L}$. [13-15] The increase in vancomycin MIC but within the susceptible range of MRSA is called the creep phenomenon.[16] Patients with MRSA BSIs with an elevated vancomycin MIC ( $\geq 1.5 \mathrm{mg} / \mathrm{L})$ had poor clinical outcomes i.e. longer durations of bacteremia, higher recurrence rate of MRSA bacteremia after vancomycin discontinuation, longer hospital stays, and increased mortality. [17-19] In addition, the number of patients infected with MRSA with a vancomycin $\mathrm{MIC} \leq 0.5 \mathrm{mg} / \mathrm{L}$ was associated with treatment success if compared with those infected with strains of vancomycin MIC of 1-2 mg/L.[20]

We conducted this study along the same lines as the one conducted from 2007-2011 which aimed to describe the epidemiology, characteristics, mortality rate, and risk factors of death among patients who had MRSA BSIs. In addition, we also determines vancomycin MIC among MRSA isolates from hemoculture. Vancomycin MIC was routinely performed for blood cultures growing MRSA in our hospital from 2012.

\section{Methods}

A retrospective study was conducted at the Maharaj Nakorn Chiang Mai hospital, a 1400-bed, university affiliated hospital in northern Thailand. Adult inpatients aged $\geq 18$ years and had MRSA grown from blood culture from January 2013 to December 2017 were enrolled. Demographic and clinical characteristics, laboratory information, and microbiological data were collected.

\section{Microbiological methods}

Bacterial identification and antimicrobial susceptibility testing were performed at the Microbiology unit, Diagnostic laboratory, Maharaj Nakorn Chiang Mai hospital. S. aureus was identified by conventional biochemical tests. All $S$. aureus isolates were tested against 5 antibiotics including oxacillin (using cefoxitin as a surrogate drug), vancomycin, trimethoprim-sulfamethoxazole, erythromycin and clindamycin by disk diffusion method following the Clinical and Laboratory Standards Institute (CLSI) guidelines, M02-A11 [21] and M02-A12.[22] The disk diffusion results were interpreted according to the breakpoints stated in the CLSI guidelines, M-100 series.[22] A further minimal inhibitory concentration (MIC) test of vancomycin was performed among the MRSA samples isolated from blood cultures. MIC is 
the lowest concentration of a chemical which prevents visible growth of a bacterium. According to the CLSI, MRSA can be categorized into 3 groups: MIC $\leq 2 \mathrm{mg} / \mathrm{L}$ refers to vancomycin-susceptible $S$.aureus; MIC 4-8 mg/L refers to vancomycin-intermediate resistant $S$. aureus (VISA), and MIC $\geq 16 \mathrm{mg} / \mathrm{L}$ refers to vancomycin-resistant S.aureus (VRSA).[22]

\section{Statistical analysis}

Data were presented as numbers (\%), means and standard deviation (SD), or medians and interquartile ranges (IQR) as appropriate. Characteristics between groups were compared using the Student's t-test, Mann-Whitney Utest, Chi-square test or Fisher's exact test as appropriate. Factors associated with mortality were analyzed using a univariate logistic regression model. Variables with a p-value $<0.10$ from the univariate analysis were then tested in a multivariate logistic regression model using a backward stepwise procedure. A two-sided test with a $p$-value of $<0.05$ was used to determine statistical significance. All statistical analyses were performed using Stata statistical software version 10.0 (Stata Statistical Software: Release 10.0, Stata Corporation, College Station, TX).

This study was approved by the Faculty of Medicine Ethical Committee, approval number MED-256105488.

\section{Results}

The prevalence of MRSA among S.aureus BSIs from 2013 to 2017 were 32.8, 23.1, 26.8, 19.2 and 15.4\%, respectively ( $p$-value for trend $=0.086$ ). Eighty-four patients with MRSA BSIs were enrolled; the numbers of patient in $2013,2014,2015,2016$ and 2017 were $22,16,19,15$, and 12, respectively.

\section{Demographic data}

Fifty-three patients (63.1\%) were male. The median age was 68.5 years (IQR 56, 79). Twenty-four patients $(28.6 \%)$ were admitted to the intensive care unit (ICU). The details of hospital units is shown in Table 1. Seventy-two patients (85.7\%) had underlying diseases. The 5 most common underlying diseases were, in decreasing order: hypertension, chronic kidney disease, diabetic mellitus, dyslipidemia and malignancy (Table 1). Patients who had previous hospitalization within 3 months numbered 45 (53.6\%), and prior antibiotic use within 3 months were 73 patients (86.9\%). 
Table 1

Demographic characteristic of patients who had MRSA bloodstream infections

\begin{tabular}{|ll|}
\hline Characteristics & Number (\%) \\
\hline Male & $\mathbf{N}=84$ \\
\hline Age in years (median, IQR) & $53(63.1)$ \\
\hline Presence of underlying disease & $68.5(56,79)$ \\
\hline - Hypertension & $72(85.7)$ \\
\hline - Chronic kidney disease & $32(38.1)$ \\
\hline - Diabetes mellitus & $31(36.9)$ \\
\hline - Dyslipidemia & $16(19.3)$ \\
\hline - Malignancy & $14(16.7)$ \\
\hline - Chronic obstructive pulmonary disease & $14(16.7)$ \\
\hline - Cerebrovascular accident & $8(9.5)$ \\
\hline - Valvular heart disease & $8(9.5)$ \\
\hline - Dilated cardiomyopathy & $6(7.1)$ \\
\hline - Coronary artery disease & $5(6.0)$ \\
\hline - History of surgery of aortic arterial aneurysm & $4(4.8)$ \\
\hline - Bronchiectasis & $1(1.2)$ \\
\hline - Human immunodeficiency virus & $1(1.2)$ \\
\hline Prior hospitalization within 3 months & $45(53.6)$ \\
\hline Prior antibiotic within 3 months & $73(86.9)$ \\
\hline Beta-lactams antibiotics: & $3(3.6)$ \\
\hline - Cloxacillin & $23(27.4)$ \\
\hline - Ampicillin & $7(8.3)$ \\
\hline - Amoxicillin/clavulanate & $3(3.6)$ \\
\hline - Piperacillin/tazobactam & $4(4.8)$ \\
\hline - Cefazolin & $25(29.8)$ \\
\hline - Ceftriaxone & \\
\hline
\end{tabular}




\begin{tabular}{|ll|}
\hline Characteristics & Number (\%) \\
\hline - Ceftazidime & $\mathbf{N 4}$ \\
\hline - Cefoperazone/sulbactam & $6(7.1)$ \\
\hline - Ertapenem & $2(2.4)$ \\
\hline - Imipenem/cilastatin & $7(8.3)$ \\
\hline - Meropenem & $5(6.0)$ \\
\hline Others: & $37(44.1)$ \\
\hline - Azithromycin & \\
\hline - Ciprofloxacin & $7(8.3)$ \\
\hline - Clindamycin & $14(16.7)$ \\
\hline - Colistin & $11(13.1)$ \\
\hline - Fosfomycin & $19(22.6)$ \\
\hline - Levofloxacin & $2(2.4)$ \\
\hline - Metronidazole & $1(1.2)$ \\
\hline - Trimethoprim/sulfamethoxazole & $2(2.4)$ \\
\hline - Vancomycin & $1(1.2)$ \\
\hline Unit of admission & $12(14.3)$ \\
\hline - General internal medicine & $1(1.2)$ \\
\hline - Intensive care of internal medicine & $20(23.8)$ \\
\hline - General surgery & $3(9.5)$ \\
\hline - Intensive care of surgery & $4(4.8)$ \\
\hline - General orthopedics & $17.9)$ \\
\hline - Intensive care of orthopedics & \\
\hline
\end{tabular}

\section{Clinical characteristics}

Fifty-eight patients (69\%) had bloodstream infections with concurrent other sites of infection: pneumonia 28 episodes (43.1\%), skin and soft tissue infections 16 episodes (24.6\%), osteomyelitis 7 episodes (10.8\%), infective endocarditis 4 episodes (6.2\%), septic arthritis 4 episodes $(6.2 \%)$, arterial graft infections 4 episodes (6.2\%) and urinary tract infections 2 episodes (3.1\%). Sixty-five patients $(77.4 \%)$ had medical devices inserted: central venous catheter 45 patients (53.6\%), urinary catheter 43 patients 
(51.2\%), nasogastric tube 40 patients (47.6\%), and endotracheal tube 39 patients (46.4\%). Sixty-one patients $(72.6 \%)$ had a body temperature $\geq 38.0^{\circ} \mathrm{C}$, and 10 patients $(11.9 \%)$ had blood pressure < $90 / 60 \mathrm{~mm} . \mathrm{Hg}$. Forty-eight patients $(57.1 \%)$ had alteration of consciousness (Table 2 ) 
Table 2

Clinical characteristics and laboratory data of patients infected with MRSA bloodstream infections

\begin{tabular}{|ll|}
\hline Characteristics & Values \\
& $(\mathbf{N}=84)$ \\
\hline Presence of medical devices & $65(77.4)$ \\
\hline - Central venous catheter & $45(53.6)$ \\
\hline - Urinary catheter & $43(51.2)$ \\
\hline - Nasogastric tube & $40(47.6)$ \\
\hline - Endotracheal tube & $39(46.6)$ \\
\hline Signs and symptoms & \\
\hline - Alteration of consciousness & $48(57.1)$ \\
\hline - Body temperature $\geq 38.0{ }^{\circ} \mathrm{C}$ & $61(72.6)$ \\
\hline - Blood pressure $<90 / 60$ mm.Hg & $10(11.9)$ \\
\hline - Tachycardia (heart rate $\geq 120$ beat/minute) & $26(31.0)$ \\
\hline - Tachypnea (respiratory rate $>20 /$ minute) & $55(65.5)$ \\
\hline Site of infections: & \\
\hline - Primary blood stream infection (BSI) & $26(31.0)$ \\
\hline - BSI with pneumonia & $28(33.3)$ \\
\hline - BSI with skin and soft tissue infection & $16(19.1)$ \\
\hline - BSI with osteomyelitis & $7(8.3)$ \\
\hline - BSI with infective endocarditis & $4(4.8)$ \\
\hline - BSI with septic arthritis & $4(4.8)$ \\
\hline - BSI with arterial graft infection & $4(4.8)$ \\
\hline - BSI with urinary tract infection & $2(2.4)$ \\
\hline Laboratory findings: & \\
\hline - Hemoglobin (g/dL) & $(7.9 .5,89.7)$ \\
\hline - White blood cell count (cell/cu.mm.) & \\
\hline - Neutrophil (\%) & \\
\hline
\end{tabular}

Data are presented as number (\%), mean ( \pm SD), or median (IQR) as appropriate 


\begin{tabular}{|c|c|}
\hline Characteristics & $\begin{array}{l}\text { Values } \\
(\mathrm{N}=84)\end{array}$ \\
\hline - Lymphocyte (\%) & $7.3(4.2,12.2)$ \\
\hline - Platelet (x1000/cu.mm.) & $207(110.5,272)$ \\
\hline - Creatinine (mg/dl) & $2.1(0.9,4.4)$ \\
\hline - Albumin (mg/dl) & $2.5 \pm 0.6$ \\
\hline - Aspartate aminotransferase (IU/L) & $32(21,74)$ \\
\hline - Vancomycin MIC (mg/L) & $1.3 \pm 0.4$ \\
\hline \multicolumn{2}{|c|}{ Data are presented as number $(\%)$, mean $( \pm S D)$, or median (IQR) as appropriate } \\
\hline
\end{tabular}

All isolates were susceptible to vancomycin according to CLSI guidelines. Sixty-three isolates (75\%) were susceptible to trimethoprim/sulfamethoxazole, 3 isolates (3.6\%) susceptible to clindamycin, and 4 isolates (4\%) were susceptible to erythromycin.

\section{Vancomycin MIC}

Three patients had missing vancomycin MIC, 1 in each of the years 2013, 2015, and 2017. That means vancomycin MICs from 2013 to 2017 were 1.45, 1.47, 1.24, 1.02 and $1.50 \mathrm{mg} / \mathrm{L}$, respectively. Percentage of patients with vancomycin MICs $\geq 1.5 \mathrm{mg} / \mathrm{L}$ were $68.2 \%, 62.5 \%, 47.4 \%, 26.7 \%$, and $75 \%$ from 2013 to 2017, respectively $(p=0.325)$ (Fig. 1$)$.

\section{Treatment and outcome}

Seventy-nine patients received anti-MRSA treatment; 72 patients (85.7\%) received vancomycin, 5 patients $(6.0 \%)$ received linezolid, and 2 patients $(2.4 \%)$ received fosfomycin. The median time from positive blood culture to receipt og appropriate antibiotics was 1 day (IQR 0,3$)$. The other 5 patients did not receive antiMRSA treatment and died.

Fifty-four patients died giving a mortality rate of $64.3 \%$. The patients who died were more likely to be older, had had prior use of piperacillin/tazobactam within 3 months, presence of alteration of consciousness, tachypnea, presence of medical devices, had concurrent pneumonia, and lower platelet count. Patients who survived were more likely to have an underlying condition of chronic kidney disease. (Tables 3 and 4) 
Table 3

Comparisons of demographic characteristics between patients who survived and who died

\begin{tabular}{|c|c|c|c|}
\hline Variables & $\begin{array}{l}\text { Patients } \\
\text { who survived } \\
\mathrm{N}(\%) \\
(\mathrm{N}=30)\end{array}$ & $\begin{array}{l}\text { Patients who died } \\
N(\%) \\
(N=54)\end{array}$ & P-values \\
\hline Male & $19(63.3)$ & $19(63.3)$ & 0.973 \\
\hline Age in years (median, IQR) & $63(54,72)$ & $74.5(61,83)$ & 0.004 \\
\hline Presence of underlying diseases: & $25(83.3)$ & $47(87.0)$ & 0.748 \\
\hline - Hypertension & $11(36.7)$ & $21(38.9)$ & 0.841 \\
\hline - Chronic kidney disease & $16(53.3)$ & $15(27.8)$ & 0.020 \\
\hline - Diabetes mellitus & $9(30.0)$ & $7(13.2)$ & 0.062 \\
\hline - Malignancy & $4(13.3)$ & $10(18.5)$ & 0.761 \\
\hline - Chronic obstructive pulmonary diseases & $2(6.7)$ & $6(11.1)$ & 0.705 \\
\hline - Cerebrovascular accident & $3(10.0)$ & $5(9.3)$ & 1.000 \\
\hline - Valvular heart disease & $1(3.3)$ & $5(9.3)$ & 0.414 \\
\hline - Dilated cardiomyopathy & $1(3.3)$ & $4(7.4)$ & 0.651 \\
\hline - Coronary artery disease & $1(3.3)$ & $4(7.4)$ & 0.651 \\
\hline - History of surgery abdominal aortic aneurysm & $2(6.7)$ & $2(3.7)$ & 0.614 \\
\hline Prior hospitalization within 3 months & $15(50.0)$ & $30(55.6)$ & 0.625 \\
\hline Prior antibiotic within 3 months & $25(83.3)$ & $48(88.9)$ & 0.511 \\
\hline \multicolumn{4}{|l|}{ Beta-lactam antibiotics: } \\
\hline - Cloxacillin & $4(13.3)$ & $3(5.6)$ & 0.242 \\
\hline - Amoxicillin/clavulanate & $1(3.3)$ & $3(5.6)$ & 1.000 \\
\hline - Piperacillin/tazobactam & $3(10.0)$ & $22(40.7)$ & 0.003 \\
\hline - Cefazolin & $2(6.7)$ & $1(1.9)$ & 0.289 \\
\hline - Ceftriaxone & $6(20.0)$ & $17(31.5)$ & 0.258 \\
\hline - Ceftazidime & $3(10.0)$ & $3(5.6)$ & 0.662 \\
\hline - Ertapenem & $4(13.3)$ & $3(5.6)$ & 0.242 \\
\hline - Imipenem/cilastatin & $2(6.7)$ & $7(13.0)$ & 0.480 \\
\hline
\end{tabular}




\begin{tabular}{|llll|}
\hline Variables & $\begin{array}{l}\text { Patients } \\
\text { who survived }\end{array}$ & $\begin{array}{l}\text { Patients who died } \\
\mathbf{N}(\%)\end{array}$ & P-values \\
& $\begin{array}{l}\mathbf{N}(\%) \\
\mathbf{N}=\mathbf{3 0})\end{array}$ & & \\
\hline - Meropenem & $11(36.7)$ & $26(48.2)$ & 0.310 \\
\hline Others: & & & \\
\hline - Azithromycin & $2(6.7)$ & $5(9.3)$ & 1.000 \\
\hline - Ciprofloxacin & $7(23.3)$ & $7(13.0)$ & 0.222 \\
\hline - Clindamycin & $5(16.7)$ & $6(11.1)$ & 0.511 \\
\hline - Colistin & $3(10.0)$ & $16(29.6)$ & 0.056 \\
\hline - Metronidazole & $2(6.7)$ & $7(13.0)$ & 0.480 \\
\hline - Vancomycin & $4(13.3)$ & $8(14.8)$ & 1.000 \\
\hline Unit of admission: & & & \\
\hline - General internal medicine & $13(43.3)$ & $23(42.6)$ & 0.948 \\
\hline - Intensive care of internal medicine & $3(10.0)$ & $12(22.2)$ & 0.236 \\
\hline - General surgery & $6(20.0)$ & $14(25.9)$ & 0.541 \\
\hline - Intensive care of surgery & $4(13.3)$ & $4(7.4)$ & 0.448 \\
\hline - General orthopedics & $3(10.0)$ & $1(1.9)$ & 0.128 \\
\hline - Intensive care of orthopedics & $1(3.3)$ & $0(0.0)$ & 0.357 \\
\hline
\end{tabular}


Table 4

Comparisons of clinical characteristics between patients who survived and who and those who died

\begin{tabular}{|c|c|c|c|}
\hline Variables & $\begin{array}{l}\text { Patients who survived } \\
(\mathrm{N}=30)\end{array}$ & $\begin{array}{l}\text { Patients who } \\
\text { died } \\
(\mathrm{N}=54)\end{array}$ & $\begin{array}{l}\mathrm{P}- \\
\text { values }\end{array}$ \\
\hline Presence of medical devices & $20(66.7)$ & 45 (83.3) & 0.080 \\
\hline - Central venous catheter & $14(46.7)$ & $31(57.4)$ & 0.344 \\
\hline - Urinary catheter & $8(26.7)$ & $35(64.8)$ & 0.001 \\
\hline - Nasogastric tube & $6(20.0)$ & $34(63.0)$ & $<.001$ \\
\hline - Endotracheal tube & $6(20.0)$ & $33(61.1)$ & $\dot{0} 001$ \\
\hline \multicolumn{4}{|l|}{ Sign and symptoms } \\
\hline - Alteration of consciousness & $8(26.7)$ & $40(74.1)$ & $<.001$ \\
\hline - Body temperature $\geq 38.0^{\circ} \mathrm{C}$ & $23(76.7)$ & $38(70.4)$ & 0.616 \\
\hline - Blood pressure $<90 / 60 \mathrm{~mm} . \mathrm{Hg}$ & $2(6.7)$ & $8(14.8)$ & 0.483 \\
\hline $\begin{array}{l}\text { - Tachycardia (heart rate } \geq 120 \\
\text { beat/minute) }\end{array}$ & $8(26.7)$ & $18(33.3)$ & 0.626 \\
\hline - Tachypnea (respiratory rate > 20/ minute) & $16(53.3)$ & $39(72.2)$ & 0.097 \\
\hline $\begin{array}{l}\text { Bloodstream infections without other site } \\
\text { of infections }\end{array}$ & $14(46.7)$ & $12(22.2)$ & 0.020 \\
\hline \multicolumn{4}{|l|}{ Concurrent site of infections } \\
\hline - Pneumonia & $3(10.0)$ & $25(46.3)$ & 0.001 \\
\hline - Skin and soft tissue infection & $6(20.0)$ & $10(18.5)$ & 0.868 \\
\hline - Osteomyelitis & $5(16.7)$ & $2(3.7)$ & 0.092 \\
\hline - Infective endocarditis & $0(0.0)$ & $4(7.4)$ & 0.292 \\
\hline - Septic arthritis & $2(6.7)$ & $2(3.7)$ & 0.614 \\
\hline - Arterial graft infection & $2(6.7)$ & $2(3.7)$ & 0.614 \\
\hline - Urinary tract infection & $0(0.0)$ & $2(3.7)$ & 0.535 \\
\hline \multicolumn{4}{|l|}{ Laboratory findings: } \\
\hline - Hemoglobin $(\mathrm{g} / \mathrm{dL})$ & $9.1 \pm 1.6$ & $9.1 \pm 1.5$ & 0.978 \\
\hline
\end{tabular}




\begin{tabular}{|llll|}
\hline Variables & $\begin{array}{l}\text { Patients who survived } \\
(\mathbf{N}=30)\end{array}$ & $\begin{array}{l}\text { Patients who } \\
\text { died } \\
(\mathbf{N}=54)\end{array}$ & $\begin{array}{l}\text { P- } \\
\text { values }\end{array}$ \\
\hline - White blood cell count (cells/cu.mm) & 10,950 & $\begin{array}{l}12,355 \\
(8,100,19,100)\end{array}$ & 0.170 \\
\hline - Neutrophil (\%) & $(7,700,12,800)$ & $87.1(78.6,90.0)$ & 0.130 \\
\hline - Platelet (x1000/cu.mm) & $83.3(78.8,88.2)$ & 156.5 & 0.024 \\
\hline - Creatinine (mg/dL) & 234.5 & $(72,266)$ & \\
\hline - Albumin (mg/dL) & $(189,306)$ & $2.1(0.9,3.5)$ & 0.493 \\
\hline - Alanine aminotransferase (IU/L) & $2.0(0.7,6.6)$ & $2.5 \pm 0.6$ & 0.477 \\
\hline - Vancomycin MIC (mg/L) & $2.6 \pm 0.5$ & $21(13,58)$ & 0.186 \\
\hline
\end{tabular}

The multivariate analysis found that factors associated with mortality were: age $\geq 40$ years old (OR 11.35; 95\% Cl: 1.35-95.78, $p=0.026$ ), presence of alteration of consciousness (OR 11.19; 95\% Cl: $2.83-$ $44.18, p=0.001)$ and concurrent pneumonia (OR 4.44; $95 \% \mathrm{Cl}: 1.09-18.14, \mathrm{p}=0.038)$. Patients with chronic kidney disease were associated with survival. There was no significant difference in mortality rate between those infected with MRSA with vancomycin MIC $\leq 1$ and $>1 \mathrm{mg} / \mathrm{L}(p=0.617)$.

\section{Discussion}

This study demonstrated that the prevalence of MRSA among S.aureus BSIs was non-significantly decreasing over this 5 -year period, from $33-15 \%$. This finding is in contrast with our study conducted between 2007 and 2011, in which there was an increasing prevalence, doubling from 23-43\%. [7] The SENTRY study reported a prevalence of $37.8 \%$ in the period $1997-2000$, reaching a peak of $45.3 \%$ in 2005-2008, slightly declining to 40.0\% from 2013-2016.[3] The surveillance of antimicrobial resistance in Europe in 2018 showed a large difference in MRSA percentages ranging from $0-43 \%$, giving an average rate of $16.4 \%$ in 2018 . Almost one-third of European countries reported a significant decrease in the resistance rate from 2015-2018. [23] The decreasing trend in many countries may be attributed to the new technology enabling early detection of MRSA, leading to prompt initiation of appropriate antibiotics to reduce colonization pressure and improvement in infection control measures.

Demographic and clinical characteristics are comparable to the previous reports. The majority of patients had underlying diseases, had prior exposure to antibiotics within 3 months, and had medical devices inserted. Seventy percent of patients had concurrent other infections; $33 \%$ of patients had pneumonia and $19 \%$ of patients had skin and soft tissue infection. $[6,7,24]$. All clinical isolates were sensitive to vancomycin according to vancomycin MIC. 
Vancomycin is a life-saving medication, and has been the mainstay of treatment for MRSA infections for several years. Although new medication i.e. linezolid, daptomycin, and ceftalorine is available, [25] they are not widely accessible for the majority of patients in Thailand, mainly due to high cost. Vancomycin has a narrow therapeutic index, high levels can cause toxicity and low levels can result in treatment failure. [26] Therefore, drug level must be monitored for patients receiving vancomycin. A level of 15$20 \mathrm{mg} / \mathrm{L}$ is required for treatment success of BSIs.[26, 27] The pharmacokinetics (Pk)/ pharmacodynamics $(\mathrm{Pd})$ parameter of vancomycin, which is the area under the curve (AUC) above the minimal inhibitory concentration (MIC) of $>400$ is correlated with good clinical outcome.[27] However, in the era of vancomycin MIC creeps, higher drug levels may be required to achieve that Pk/Pd parameter. In the past, vancomycin MICs were mostly $<0.5 \mathrm{mg} / \mathrm{L}$. $[28,29]$ however, many reports demonstrated that vancomycin MICs are increasing.[16, 28-30] A study in the US, reported a vancomycin MIC $\geq 1 \mathrm{mg} / \mathrm{L}$ from 2000-2008. [30] In China, the percentages of vancomycin MIC $=1 \mathrm{mg} / \mathrm{L}$ increased from $37.0 \%$ in 2006 to $75.7 \%$ in 2010. (25) In this current study, vancomycin MIC for each year was mostly $\geq 1 \mathrm{mg} / \mathrm{dL}$. Sixteen patients $(19.7 \%)$ had vancomycin MIC $=2 \mathrm{mg} / \mathrm{L}$. There are conflicting data with regard to the association between treatment failure and an MIC of $1.5 \mathrm{mg} / \mathrm{L}$ or greater. $[18,19,31,32]$ This study demonstrated no association between mortality and an MIC of $1.5 \mathrm{mg} / \mathrm{L}$ or greater. Given a vancomycin MIC of $\leq 1.5 \mathrm{mg} / \mathrm{L}$, vancomycin is still a mainstay of treatment for MRSA infection in our hospital. However, as some strains had an MIC of $2.0 \mathrm{mg} / \mathrm{L}$, clinicians should be aware of MIC creep and monitor the position continuously.

A systematic review and meta-analysis reported mortality rates of MRSA BSI, ranging from 14.2-41.8\% between 2006 and 2011.[18] Our previous study which was conducted between 2007 and 2011 reported a mortality of 53.1\%. [7] Mortality rate among those who had vancomycin MIC $<1.5 \mathrm{mg} / \mathrm{L}$ ranged from 9 and $39 \%$ and those who had vancomycin MIC $\geq 1.5 \mathrm{mg} / \mathrm{L}$ ranged from 5 and $66 \%$. [18] Not all studies demonstrated a higher mortality rate among those who had MIC $\geq 1.5 \mathrm{mg} / \mathrm{L}$.

Factors associated with death included older age, presence of alteration of consciousness and concurrent pneumonia. Aging is associated with low immunity, [33] alteration of consciousness may represent signs of sepsis, $[34,35]$ and concurrent pneumonia may be associated with prolonged hospitalization, frequent use of medical devices and broad-spectrum antimicrobials, which may directly or indirectly lead to fatal outcome. In addition to those factors, other studies also reported that those receiving corticosteroids, requiring mechanical ventilation, had sepsis or septic shock, and failure to receive anti-MRSA antibiotics within 24 hours of MRSA identification all had a higher incidence of fatality. [36-38] Chronic kidney disease reduced the risk of mortality as these patients, particularly those receiving renal replacement therapy, are acknowledged to be at risk of infection caused by MRSA or coagulasenegative staphylococci and are given early anti-MRSA therapy as a component of empirical antimicrobials.

What changed from the study carried out from 2007-2011? First, the number of cases declined and the prevalence of MRSA among $S$. aureus BSI decreased. Second, the clinical characteristics in both studies were somewhat similar i.e. majority of patients had underlying diseases, and medical devices insertion. 
Most commons concurrent infections were pneumonia and skin and soft tissue infections. Third, with data available, the means vancomyin MIC were $\geq 1 \mathrm{mg} / \mathrm{L}$. Fifty-six percent of isolates had vancomycin $\mathrm{MIC} \geq 1.5 \mathrm{mg} / \mathrm{L}$. Fourth, the mortality rate was higher in the current study, which might be explained by the fact that more patients in the current study had underlying diseases (however, we could not directly test for statistically significant difference). Finally, risk factors of death were somewhat similar.

This study had several limitations. First, due to it being a retrospective study, some data may be missing and lead to misinterpretation of the results, e.g. the leading cause of death might be due to MRSA infection itself or from other causes. Second, the number of patients recruited was small; therefore, factors associated with death may not have been detected.

\section{Conclusions}

MRSA among S.aureus BSIs shows a non-significant decrease by half from 2013 and 2017. Concurrent bloodstream infection and pneumonia increased mortality. Although the vancomycin MIC was unchanged from 2013 to 2017, more than half of the patients had vancomycin MIC $\geq 1.5 \mathrm{mg} / \mathrm{L}$. Careful monitoring of vancomycin MIC creep is crucial for selection of appropriate antibiotic therapy to prevent treatment failure.

\section{List Of Abbreviations}

BSI, bloodstream infection; CLSI, Clinical and Laboratory Standards Institute; IQR, interquartile range; mg/L, milligram/ liter; MRSA, methicillin-resistant Staphylococcus aureus, MIC, minimal inhibitory concentration; OR, odds ratio; VRSA, vancomycin-resistant Staphylococcus aureus; VISA, vancomycinintermediate resistant Staphylococcus aureus, SD, standard deviation

\section{Declarations}

\section{Ethics approval and consent to participate:}

This study was approved by the Faculty of Medicine Ethical Committee, approval number MED-256105488. Written informed consent was not obtained as we retrospectively collected the existing data.

\section{Consent for publication:}

Not applicable

\section{Availability of data and materials:}

Data will not be shared as the local IRB has no policy to share the data without prior permission. 


\section{Competing interests:}

The authors declare that they have no competing interests.

\section{Funding:}

None

\section{Authors' contributions:}

KK participated in data collection, data analysis, data interpretation, and drafted the manuscript. SY participated in data analysis and data interpretation. PK participated in data collection. RC participated in the trial design, data analysis, data interpretation, and drafted the manuscript. All authors read and approved the final manuscript.

\section{Acknowledgements:}

The authors would like to thank Mrs. Joan Elizabeth Peagamresearch administration section, Faculty of Medicine, Chiang Mai University for their provision of a native English proofreader.

\section{References}

1. Fukunaga BT, Sumida WK, Taira DA, Davis JW, Seto TB. Hospital-Acquired Methicillin-resistant Staphylococcus aureus Bacteremia Related to Medicare Antibiotic Prescriptions: A State-Level Analysis. Hawaii J Med Public Health 2016;75:303-9.

2. Cosgrove SE, Sakoulas G, Perencevich EN, Schwaber MJ, Karchmer AW, Carmeli Y. Comparison of mortality associated with methicillin-resistant and methicillin-susceptible Staphylococcus aureus bacteremia: a meta-analysis. Clin Infect Dis 2003;36:53-9.

3. Diekema DJ, Pfaller MA, Shortridge D, Zervos M, Jones RN. Twenty-Year Trends in Antimicrobial Susceptibilities Among Staphylococcus aureus From the SENTRY Antimicrobial Surveillance Program. Open Forum Infect Dis 2019;6:S47-S53.

4. Song JH, Hsueh PR, Chung DR, et al. Spread of methicillin-resistant Staphylococcus aureus between the community and the hospitals in Asian countries: an ANSORP study. J Antimicrob Chemother 2011;66:1061-9.

5. Stefani S, Chung DR, Lindsay JA, et al. Meticillin-resistant Staphylococcus aureus (MRSA): global epidemiology and harmonisation of typing methods. Int J Antimicrob Agents 2012;39:273-82.

6. Nickerson EK, Hongsuwan M, Limmathurotsakul D, et al. Staphylococcus aureus bacteraemia in a tropical setting: patient outcome and impact of antibiotic resistance. PLoS One 2009;4:e4308. 
7. Chaiwarith R, Pacharasupal P, Sirisanthana T. Epidemiology, clinical characteristics and treatment outcomes of healthcare- associated methicillin-resistant Staphylococcus aureus BLOODSTREAM infections at Chiang Mai University Hospital: a retrospective study. Southeast Asian J Trop Med Public Health 2014;45:897-905.

8. Hiramatsu K, Hanaki H, Ino T, Yabuta K, Oguri T, Tenover FC. Methicillin-resistant Staphylococcus aureus clinical strain with reduced vancomycin susceptibility. J Antimicrob Chemother 1997;40:1356.

9. Spagnolo AM, Orlando P, Panatto D, Amicizia D, Perdelli F, Cristina ML. Staphylococcus aureus with reduced susceptibility to vancomycin in healthcare settings. J Prev Med Hyg 2014;55:137-44.

10. Tenover FC, Lancaster MV, Hill BC, et al. Characterization of staphylococci with reduced susceptibilities to vancomycin and other glycopeptides. J Clin Microbiol 1998;36:1020-7.

11. Van Griethuysen A, Van 't Veen A, Buiting A, Walsh T, Kluytmans J. High percentage of methicillinresistant Staphylococcus aureus isolates with reduced susceptibility to glycopeptides in The Netherlands. J Clin Microbiol 2003;41:2487-91.

12. Trakulsomboon S, Danchaivijitr S, Rongrungruang $Y$, et al. First report of methicillin-resistant Staphylococcus aureus with reduced susceptibility to vancomycin in Thailand. J Clin Microbiol 2001;39:591-5.

13. Howden BP, Ward PB, Charles PG, et al. Treatment outcomes for serious infections caused by methicillin-resistant Staphylococcus aureus with reduced vancomycin susceptibility. Clin Infect Dis 2004;38:521-8.

14. Moise PA, Schentag JJ. Vancomycin treatment failures in Staphylococcus aureus lower respiratory tract infections. Int J Antimicrob Agents 2000;16 Suppl 1:S31-4.

15. Soriano A, Marco F, Martinez JA, et al. Influence of vancomycin minimum inhibitory concentration on the treatment of methicillin-resistant Staphylococcus aureus bacteremia. Clin Infect Dis 2008;46:193200.

16. Joana S, Pedro P, Elsa G, Filomena M. Is vancomycin MIC creep a worldwide phenomenon? Assessment of S. aureus vancomycin MIC in a tertiary university hospital. BMC Res Notes 2013;6:65.

17. Lodise TP, Graves J, Evans A, et al. Relationship between vancomycin MIC and failure among patients with methicillin-resistant Staphylococcus aureus bacteremia treated with vancomycin. Antimicrob Agents Chemother 2008;52:3315-20.

18. van Hal SJ, Lodise TP, Paterson DL. The clinical significance of vancomycin minimum inhibitory concentration in Staphylococcus aureus infections: a systematic review and meta-analysis. Clin Infect Dis 2012;54:755-71.

19. Jacob JT, DiazGranados CA. High vancomycin minimum inhibitory concentration and clinical outcomes in adults with methicillin-resistant Staphylococcus aureus infections: a meta-analysis. Int J Infect Dis 2013;17:e93-e100.

20. Sakoulas G, Moise-Broder PA, Schentag J, Forrest A, Moellering RC, Jr., Eliopoulos GM. Relationship of MIC and bactericidal activity to efficacy of vancomycin for treatment of methicillin-resistant 
Staphylococcus aureus bacteremia. J Clin Microbiol 2004;42:2398-402.

21. CLSI. Performance Standards for Antimicrobial Disk Susceptibility Tests; Approved StandardEleventh Edition. CLSI document M02-A11. Wayne, PA: Clinical and Laboratory Standards Institute; 2012.

22. CLSI. Performance Standards for Antimicrobial Disk Susceptibility Tests; Approved Standard-Twelfth Edition. CLSI document M02-A12. Wayne, PA: Clinical and Laboratory Standards Institute; 2015.

23. Surveillance of antimicrobial resistance in Europe 2018. Available from https://www.ecdc.europa.eu/en/publications-data/surveillance-antimicrobial-resistance-europe-2018 Access May 5, 2020.

24. Simor AE, Pelude L, Golding G, et al. Determinants of Outcome in Hospitalized Patients With Methicillin-Resistant Staphylococcus aureus Bloodstream Infection: Results From National Surveillance in Canada, 2008-2012. Infect Control Hosp Epidemiol 2016;37:390-7.

25. John J, Jr. The treatment of resistant staphylococcal infections. F1000Res 2020;9.

26. Kabbara WK, El-Khoury G, Chamas NR. Prospective evaluation of vancomycin therapeutic usage and trough levels monitoring. J Infect Dev Ctries 2018;12:978-84.

27. Rybak M, Lomaestro B, Rotschafer JC, et al. Therapeutic monitoring of vancomycin in adult patients: a consensus review of the American Society of Health-System Pharmacists, the Infectious Diseases Society of America, and the Society of Infectious Diseases Pharmacists. Am J Health Syst Pharm 2009;66:82-98.

28. Wang G, Hindler JF, Ward KW, Bruckner DA. Increased vancomycin MICs for Staphylococcus aureus clinical isolates from a university hospital during a 5-year period. J Clin Microbiol 2006;44:3883-6.

29. Chang W, Ma X, Gao P, Lv X, Lu H, Chen F. Vancomycin MIC creep in methicillin-resistant Staphylococcus aureus (MRSA) isolates from 2006 to 2010 in a hospital in China. Indian J Med Microbiol 2015;33:262-6.

30. Pitz AM, Yu F, Hermsen ED, Rupp ME, Fey PD, Olsen KM. Vancomycin susceptibility trends and prevalence of heterogeneous vancomycin-intermediate Staphylococcus aureus in clinical methicillinresistant S. aureus isolates. J Clin Microbiol 2011;49:269-74.

31. Song KH, Kim M, Kim CJ, et al. Impact of Vancomycin MIC on Treatment Outcomes in Invasive Staphylococcus aureus Infections. Antimicrob Agents Chemother 2017;61.

32. Yeh YC, Yeh KM, Lin TY, et al. Impact of vancomycin MIC creep on patients with methicillin-resistant Staphylococcus aureus bacteremia. J Microbiol Immunol Infect 2012;45:214-20.

33. Sadighi Akha AA. Aging and the immune system: An overview. J Immunol Methods 2018;463:21-6.

34. Adam N, Kandelman S, Mantz J, Chretien F, Sharshar T. Sepsis-induced brain dysfunction. Expert Rev Anti Infect Ther 2013;11:211-21.

35. Cotena S, Piazza O. Sepsis-associated encephalopathy. TransI Med UniSa 2012;2:20-7.

36. Forstner C, Dungl C, Tobudic S, Mitteregger D, Lagler H, Burgmann H. Predictors of clinical and microbiological treatment failure in patients with methicillin-resistant Staphylococcus aureus 
(MRSA) bacteraemia: a retrospective cohort study in a region with low MRSA prevalence. Clin Microbiol Infect 2013;19:E291-7.

37. Kim T, Chong YP, Park KH, et al. Clinical and microbiological factors associated with early patient mortality from methicillin-resistant Staphylococcus aureus bacteremia. Korean J Intern Med 2019;34:184-94.

38. Lee HY, Chen CL, Liu SY, Yan YS, Chang CJ, Chiu CH. Impact of Molecular Epidemiology and Reduced Susceptibility to Glycopeptides and Daptomycin on Outcomes of Patients with Methicillin-Resistant Staphylococcus aureus Bacteremia. PLoS One 2015;10:e0136171.

\section{Figures}

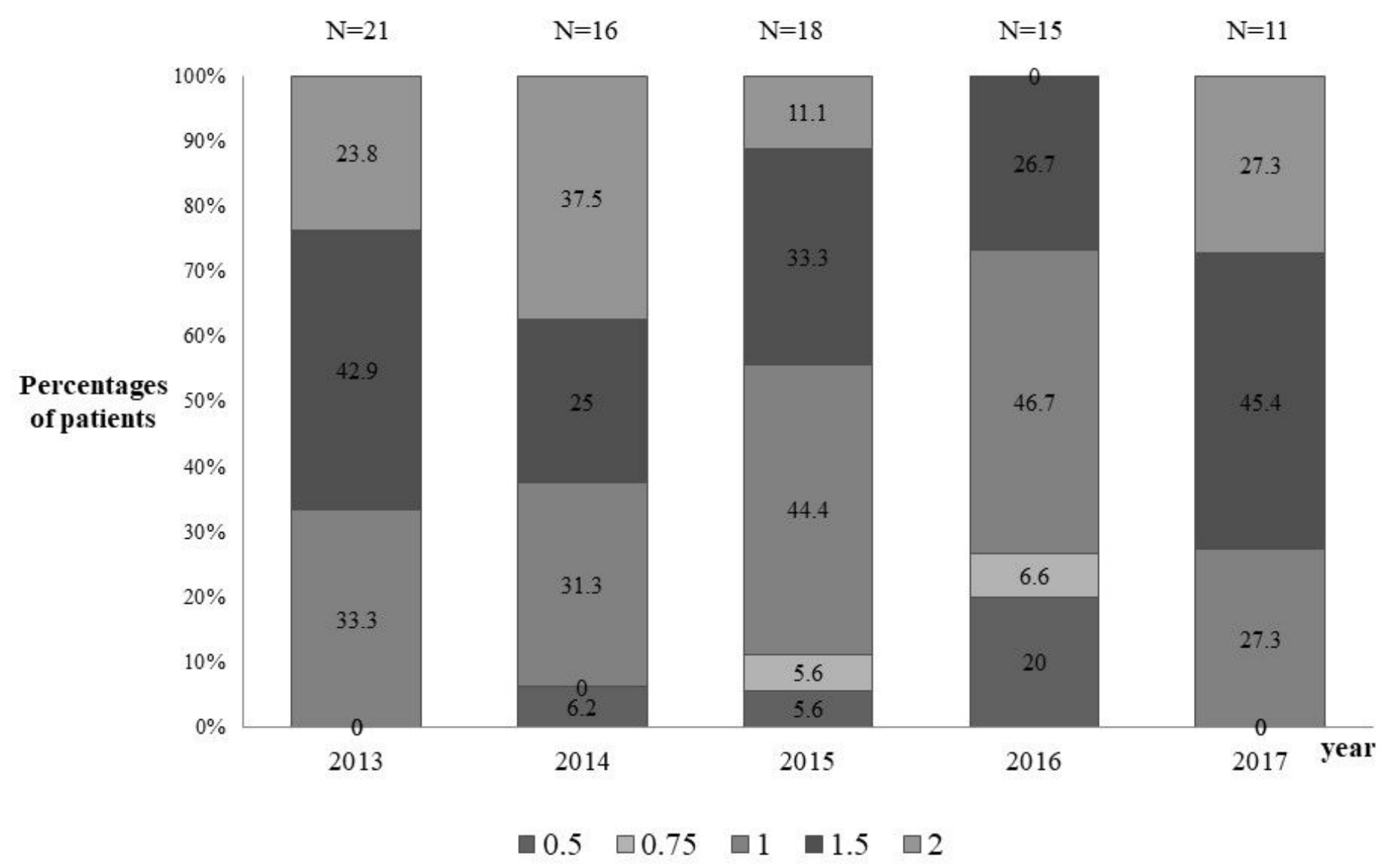

\section{Figure 1}

Distribution of vancomycin MIC by calendar year 